\title{
Inhibition of Corn Oil Peroxidation by Extracts from Defatted Seeds of Camellia oleifera Abel
}

\author{
Haiming Chen, ${ }^{1}$ Fei Song, ${ }^{1,2}$ Weijun Chen, ${ }^{1}$ and Wenxue Chen ${ }^{1}$ \\ ${ }^{1}$ College of Food Science and Technology, Hainan University, Haikou, Hainan 570228, China \\ ${ }^{2}$ Coconut Research Institute, Chinese Academy of Tropical Agricultural Sciences, Wenchang, Hainan 571339, China \\ Correspondence should be addressed to Weijun Chen; chenwj@hainu.edu.cn and Wenxue Chen; hnchwx@163.com
}

Received 9 June 2017; Revised 1 August 2017; Accepted 20 August 2017; Published 2 October 2017

Academic Editor: Blaž Cigić

Copyright (C) 2017 Haiming Chen et al. This is an open access article distributed under the Creative Commons Attribution License, which permits unrestricted use, distribution, and reproduction in any medium, provided the original work is properly cited.

\begin{abstract}
The defatted seed of Camellia oleifera Abel is an underexploited byproduct. In the present study, 3 solvents (isopropanol, hexane, and diethyl ether) were used to extract active compounds from defatted seeds of Camellia oleifera Abel. The qualitative and quantitative characterization of the main phenolic compounds were performed using the HPLC-DAD. In addition, the antioxidant efficacy of defatted seed extracts in the stabilization of the corn oil was estimated by monitoring its primary and secondary oxidation products. The results showed that isopropanolic extract (IE) exhibited the highest yield of total phenolic compounds $(9.23 \pm 0.33 \mathrm{mg} / \mathrm{g})$ compared with other solvents. The predominant phenolic compounds identified by HPLC-DAD in defatted seed extracts were epicatechin, naringenin, and catechin. In addition, IE exhibited the best inhibition effect on both primary and secondary oxidation products. The results reveal that IE of defatted seed of Camellia oleifera Abel is a useful antioxidant for the stabilization of corn oil.
\end{abstract}

\section{Introduction}

Vegetable oils, which are currently the preferred cooking medium, are beneficial and popular due to their cholesterollowering effects. However, they are more susceptible to oxidation than animal fats, which predominantly contain saturated fatty acids and thus do not react readily with other chemicals, especially oxygen [1]. The oxidation of lipids limits the shelf life of many products; moreover, some oxidation products are potentially toxic $[2,3]$.

Many methods have been employed to overcome lipid oxidation. These include the use of low-temperature storage to slow down the oxidation process, advanced packaging technologies to exclude oxygen and light, and antioxidants [4]. Addition of synthetic antioxidants, such as butylated hydroxyanisole (BHA), butylated hydroxytoluene (BHT), and tert-butylhydroquinone (TBHQ), is one of the most effective and popular methods to prevent oxidation and the development of off-flavors (Halliwell and Gutteridge, 1985). However, recent reports have revealed that these compounds may be associated with certain health risks, including carcinogenesis (Hou, 2003; Prior, 2004). Therefore, the use of
TBHQ for food application is banned in Japan, Canada, and Europe. Similarly, BHA has been removed from the generally recognized as safe (GRAS) list of compounds (Farag, Badei, and El Baroty, 1989).

It should be noted that oxidation is prevented in living organisms due to a number of endogenous factors, including enzymes, natural antioxidants, and chelators of metal ions [5]. Thus, there has been an increasing trend among food scientists to replace synthetic antioxidants with natural ones, which can be obtained from a wide variety of plant sources, including mustard flour [6], canola meal [7], garlic [8], old tea leaves [9], rice bran [10], wheat bran [11], and peanut hulls [12].

Camellia oleifera Abel is an evergreen shrub or small tree in the Camellia family. China is the world's largest Camellia oleifera Abel producer with 4 million hectares of Camellia oleifera Abel forest [13]. The seeds of Camellia oleifera constitute an important oil source that is extensively used to produce a specific type of cooking oil (tea oil), whose beneficial unsaturated fatty acids are comparable to those of olive oil. Four times more seed cake will be produced than tea oil. The defatted seed of Camellia oleifera is a substantial byproduct 
that is normally used as animal feed, organic fertilizer, or detergent due to its rich concentrations of polyphenols, saponins, proteins, and polysaccharides [14]. Although some studies have examined the antioxidant properties of Camellia oil, there are few reports on the efficiency of seed cake extract of Camellia oleifera in inhibiting corn oil peroxidation.

The objectives of this study were to extract active compounds from defatted seed of Camellia oleifera Abel using different solvents (isopropanol, hexane, and diethyl ether) and examine the antioxidant potential of the extracts using Folin-Ciocalteu assay. In addition, the predominant phenolic compounds of seed cake extracts were identified using HPLC-DAD. The primary and secondary oxidation products of corn oil were monitored by using the peroxide value (PV), anisidine value $(\mathrm{AV})$, conjugated dienes (CD), and thiobarbituric acid reactive substances (TBARS) values.

\section{Methods}

2.1. Materials and Chemicals. Butylated hydroxyanisole (BHT), Folin-Ciocalteau reagent, 2,4,6-tris(2-pyridyl)-1,3,5triazine (TPTZ), and $p$-anisidine and thiobarbituric acid (TBA) were purchased from Sigma-Aldrich Chemical Co. (Milwaukee, WI, USA). Phenolic acids, gallic acid, coumaric acid, catechin, epicatechin, chlorogenic acid, epicatechin, rutin, ferulic acid, naringenin, and kaempferol acid were obtained from Merck Darmstadt, Germany. Defatted seed was obtained from Dongguan Chengfu Trade Co., Ltd. (Dongguan, Guangdong, China). The refined edible corn oil without any synthetic antioxidants was obtained from a local store in Hainan. All other chemicals were of analytical grade unless otherwise mentioned.

2.2. Preparation of Seed Cake Extracts. The seed cake extracts (SCE) were prepared according to the method of Iqbal and Bhanger [8] with some modifications. The defatted seed of Camellia oleifera Abel was dried in an oven at $55^{\circ} \mathrm{C}$ until the moisture content was less than $10 \%(\mathrm{w} / \mathrm{w})$. The dried defatted seed was ground until it could pass through a $1 \mathrm{~mm}$ sieve. Then, $50 \mathrm{~g}$ (dry basis) of seed powder was extracted into $250 \mathrm{~mL}$ solvent (isopropanol, hexane, or diethyl ether). The slurry was incubated at room temperature in a vibration cultivating box at $180 \mathrm{rpm}$ for $2 \mathrm{~h}$, and the extracts were sonicated at $60^{\circ} \mathrm{C}$ for $2 \mathrm{~h}$. The extracts were filtered using filter paper, and the residue was again extracted with $200 \mathrm{~mL}$ of each solvent. The procedure was repeated thrice to ensure that the phenolic compounds were completely extracted. Next, the solvent of the filtrate was removed using a rotary evaporator at $40^{\circ} \mathrm{C}$ under reduced pressure. The products were weighed to calculate the yield and were stored under nitrogen prior to further analyses.

2.3. Determination of Total Phenolic Compounds. The total phenolic content of the samples was determined using the Folin-Ciocalteau method [15]. Briefly, each individual extract $(0.1 \mathrm{~mL})$ was diluted to $1 \mathrm{~mL}$ with distilled water, and $0.5 \mathrm{~mL}$ of Folin-Ciocalteu reagent and $2 \mathrm{~mL}$ of $\mathrm{Na}_{2} \mathrm{CO}_{3}$ solution $(7.5 \%, \mathrm{w} / \mathrm{w})$ were added. The solutions were mixed thoroughly and incubated at $40^{\circ} \mathrm{C}$ for $30 \mathrm{~min}$. The absorbance was detected at $765 \mathrm{~nm}$ on a Perkin-Elmer Lambda-2 Spectrophotometer with a $1 \mathrm{~cm}$ cell. Gallic acid was used as a standard, and the results were expressed as gallic acid in terms of milligram gallic acid equivalents in every gram of dried SCE. The reaction was conducted in triplicate, and the results were averaged.

2.4. Identification of Phenolic Compounds Using HPLC-DAD. The phenolic compounds of defatted seed extracts were identified using the HPLC-DAD method as reported by Chirinos et al. [16]. HPLC analysis was performed using Shimadzu LC-20A pumps with a diode array detector (DAD), and chromatographic separations were performed on a Phenomenex C18 column $(250 \mathrm{~mm} \times 4.6 \mathrm{~mm}$, particle size $5 \mathrm{~mm}$ ). The composition of solvents and gradient elution conditions were as follows. The mobile phase was composed of solvent (A) water:acetic acid (97:3, v/v, $\mathrm{pH} 2.27)$ and solvent (B) methanol. The solvent gradient was as follows: $10-30 \%$ B for $0-6 \mathrm{~min}, 30-70 \%$ B for $6-10 \mathrm{~min}, 70-90 \%$ B for $10-15 \mathrm{~min}, 90-100 \%$ B for $15-20 \mathrm{~min}, 100-20 \%$ B for 20-25 min, and holding $20 \%$ B for $25-30 \mathrm{~min}$. A flow rate of $1.0 \mathrm{~mL} / \mathrm{min}$ was used, and $10 \mu \mathrm{L}$ samples were injected. All samples and mobile phases were filtered through a $0.22 \mu \mathrm{m}$ Millipore filter before injection. Each fraction was analyzed in duplicate.

2.5. Ferric Reducing Antioxidant Power (FRAP) Assay. The FRAP assay was conducted according to Benzie and Strain (1996) with some modifications. The working FRAP reagent was freshly prepared by mixing $25 \mathrm{~mL}$ acetate buffer (300 mM, pH 3.6), $2.5 \mathrm{~mL}$ TPTZ solution $(10 \mathrm{mM})$, and $2.5 \mathrm{~mL} \mathrm{FeCl}_{3} \cdot 6 \mathrm{H}_{2} \mathrm{O}$ solution $(20 \mathrm{mM})$. The mixture was kept at $37^{\circ} \mathrm{C}$ before use, and a reagent blank reading was taken at $593 \mathrm{~nm}$. SCE $(100 \mu \mathrm{L})$ were allowed to react with $2.85 \mathrm{~mL}$ FRAP solution for $30 \mathrm{~min}$ in the dark, and the absorbance was read at $593 \mathrm{~nm}$. The Trolox was used as the standard, and the standard curve was linear between 25 and $800 \mu \mathrm{M}$ Trolox. The results were expressed in $\mathrm{mM}$ Trolox equivalent antioxidant capacity (TEAC)/g dried SCE. Additional dilutions were needed if the measured FRAP value was over the linear range of the standard curve.

2.6. Measurement of Peroxide Value (PV), Conjugated Dienes $(C D)$, Anisidine Value (AV), and Thiobarbituric Acid Reactive Substances (TBARS). The antioxidant activity of the collected SCE extracts (IE, NE, and DE) on corn oil was evaluated using the $\mathrm{PV}, \mathrm{CD}, \mathrm{AV}$, and TBARS values. $\mathrm{PV}$ was determined according to the iodine colorimetry reported by AOAC. The extracts of SCE and the synthetic antioxidant were dissolved in a minimum amount of absolute methanol and added to $100 \mathrm{~g}$ corn oil after mixing for $10 \mathrm{~min}$ to achieve different concentration of $0.25 \%$ and $0.5 \%(\mathrm{w} / \mathrm{v})$ for SCE and $0.02 \%$ $(\mathrm{w} / \mathrm{v})$ for BHT. After being stored for different times, samples $(5 \mathrm{~g})$ were dissolved in $30 \mathrm{~mL}$ of acetic acid/chloroform $(3: 2$, $\mathrm{v}: \mathrm{v})$ solution, with the addition of $0.5 \mathrm{~mL}$ of a saturated solution of potassium iodide and a $1 \%$ starch solution as an indicator. The mixture was allowed to stand for $1 \mathrm{~min}$ and then $30 \mathrm{~mL}$ of distilled water and $0.5 \mathrm{~mL}$ of $1 \%$ starch were added. The liberated iodine was titrated with a sodium 
TABLE 1: Total extractable compounds (TEC), total phenolic compounds (TPC), and the proportion of TPC in TEC ${ }^{A}$.

\begin{tabular}{lccc}
\hline Extraction & TEC $(\mathrm{mg} / \mathrm{g}$ dried seed cake $)$ & TPC $(\mathrm{mg} / \mathrm{g}$ dried seed cake $)$ & TPC/TEC $(\mathrm{mg} / \mathrm{g}$ dried SCE $)$ \\
\hline $\mathrm{IE}^{\mathrm{B}}$ & $180.1 \pm 1.78^{\mathrm{c}}$ & $9.23 \pm 0.33^{\mathrm{c}}$ & 51.25 \\
$\mathrm{NE}$ & $123.3 \pm 2.35^{\mathrm{b}}$ & $6.45 \pm 0.61^{\mathrm{b}}$ & 52.31 \\
$\mathrm{DE}$ & $95.7 \pm 1.39^{\mathrm{a}}$ & $3.86 \pm 0.48^{\mathrm{a}}$ & 40.33 \\
\hline
\end{tabular}

${ }^{\mathrm{A}}$ Assays were performed in triplicate. Mean $\pm \mathrm{SD}$ values in the same column with different superscript letter are significantly different $(p<0.05)$; ${ }^{\mathrm{B}} \mathrm{IE}$, isopropanol extract; NE, normal hexane extract; DE, diethyl ether extract; SCE, seed cake extract.

thiosulfate solution $\left(0.1 \mathrm{~mol} \mathrm{~L}^{-1}\right)$ until the blue color disappeared. A blank test was also conducted under the same conditions as described with the samples. The peroxide value was calculated as follows:

$$
\text { Peroxide value }=\frac{(B-A) \times N \times f \times 100}{m},
$$

where $A$ is the volume $(\mathrm{mL})$ of the standard volumetric sodium thiosulfate solution used for the blank test, $B$ is the volume $(\mathrm{mL})$ of the standard volumetric sodium thiosulfate solution used for the sample titration, $N$ is the normal concentration of the standard volumetric sodium thiosulfate solution used, $f$ is the correction factor, and $m$ is the mass of the sample $(\mathrm{kg})$.

The $p$-AV of the samples was measured using a spectrophotometer [3]. PV and AV, which were used as indicators for the primary and secondary oxidation of the corn oil, were determined at $4,8,16,24,32,48$, and $72 \mathrm{~h}$, and all treatments were carried out three times.

$\mathrm{CD}$ value was determined according to the method of Shahidi et al. [2]. The absorbance of the samples was determined. Each sample $(10 \mathrm{~mL})$ was thoroughly mixed with $10 \mathrm{~mL}$ isooctane. The absorbance was read at $234 \mathrm{~nm}$ after samples had been stored for $0,1,2$, and 3 days. Pure isooctane was used as a reference. The $\mathrm{CD}$ value, expressed as percentage of conjugated dienoic acid, was calculated according to the equation below:

$$
\mathrm{CD} \text { value }=\frac{A}{C \times 1}
$$

where $\mathrm{CD}$ is conjugated diene, $A$ is absorbance at $234 \mathrm{~nm}, C$ is concentration $(\mathrm{g} / 100 \mathrm{ml})$, and $l$ is path length $(\mathrm{cm})$.

The TBARS values of the samples were tested and analyzed over $0,1,2$, and $3 \mathrm{~d}$ periods as described by Shahidi et al. [2] with some modification. Briefly, each sample (200 mg) was weighed accurately and transferred into a centrifuge tube to which $5 \mathrm{~mL}$ of 1-butanol TCA was added and vortexed at a high speed for $2 \mathrm{~min}$. A quantity of $5 \mathrm{~mL}$ aqueous solution of TBA $(0.02 \mathrm{M})$ was then added to each centrifuge tube, which was then vortexed for an additional $30 \mathrm{~s}$. The samples were then centrifuged at $3,000 \times \mathrm{g}$ for $10 \mathrm{~min}$, and the supernatants were filtered through Whatman \#3 filter paper. The tubes were placed in a water bath at $95^{\circ} \mathrm{C}$ for $120 \mathrm{~min}$ and cooled to room temperature. The absorbance value of solutions was read at $532 \mathrm{~nm}$. The TBARS value was calculated according to the equation below:

$$
\text { TBARS value }=\frac{A \times 0.145}{m},
$$

where $A$ is absorbance at $532 \mathrm{~nm}$ and $m$ is the mass of the sample.

\section{Results and Discussion}

3.1. Extraction of Phenolic Compounds. Total extractable compounds (TEC), total phenolic compounds (TPC) using different solvents, and the proportion of TPC in TEC are shown in Table 1. It is clear that the extraction abilities of isopropanol, normal hexane, and diethyl ether used for the extraction of the COC were significantly different $(p<0.05)$. In general, the TEC of IE, NE, and DE were $180.1 \pm 1.78$, $123.3 \pm 2.35$, and $95.7 \pm 1.39 \mathrm{mg} / \mathrm{g}$, respectively. The result suggested that TEC depended on the extraction medium, which is consistent with results reported by Shahidi et al. [2].

The TPC contents of IE, NE, and DE from COC had the same trend as did the experimental results of TEC. The results showed that IE contained the highest amount of TPC (9.23 \pm $0.33 \mathrm{mg} / \mathrm{g})$, followed by NE $(6.45 \pm 0.61 \mathrm{mg} / \mathrm{g})$ and DE $(3.86 \pm$ $0.48 \mathrm{mg} / \mathrm{g}$ ). The relationship between the total extractable compounds and their total phenolic compound content was represented in percentages of TPC/TEC. The total phenolic content found in the total extractable compounds ranged from 40.33 to $52.31 \mathrm{mg} / \mathrm{g}$. The amount of TPC observed in camellia oil cake extracts was greater than that observed in corn tassels $(0.16 \%)$, banana peels $(0.91 \%)$, and rice bran (3.86\%) [17-19].

\subsection{Identification of Phenolic Compounds Using HPLC-DAD.} The phenolic compounds in defatted seed extract were identified and quantified by HPLC-DAD method [20]. All samples were monitored at $280 \mathrm{~nm}$, and their spectra are shown in Figure 1. As shown in Figure 1(a), peaks 1 9 reflected nine types of phenolic acid standards: gallic acid, coumaric acid, catechin, chlorogenic acid, epicatechin, rutin, ferulic acid, naringenin, and kaempferol acid, respectively. The spectra of phenolic compounds of IE, NE, and DE are shown in Figures 1(b), 1(c), and 1(d), respectively. The species and content of the phenolic compounds of IE, NE, and DE are shown in Table 2. As shown in Figure 1, there were three main phenolic compounds (epicatechin, naringenin, and catechin) in seed extracts. Epicatechin was one of the most predominant phenolic compounds, contributing approximately $8.64 \pm$ $0.03 \mathrm{mg} / \mathrm{g}$ in IE and $9.32 \pm 0.12 \mathrm{mg} / \mathrm{g}$ in NE. However, no epicatechin or naringenin was detected in DE or NE (Table 2). Naringenin and catechin in IE contributed approximately $2.71 \pm 0.05$ and $4.00 \pm 0.04 \mathrm{mg} / 100 \mathrm{~g}$ dried SCE, respectively. 


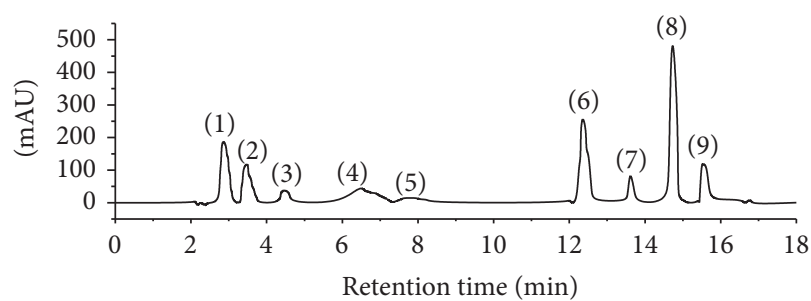

(a)

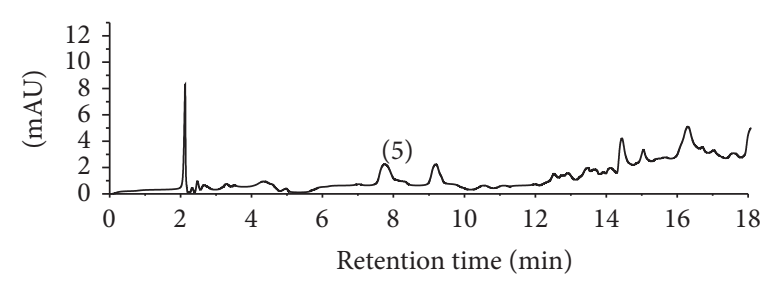

(c)

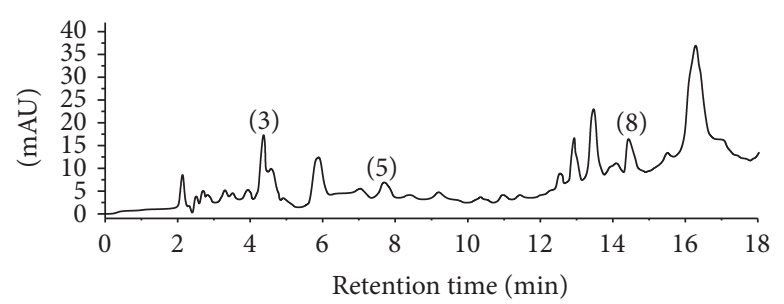

(b)

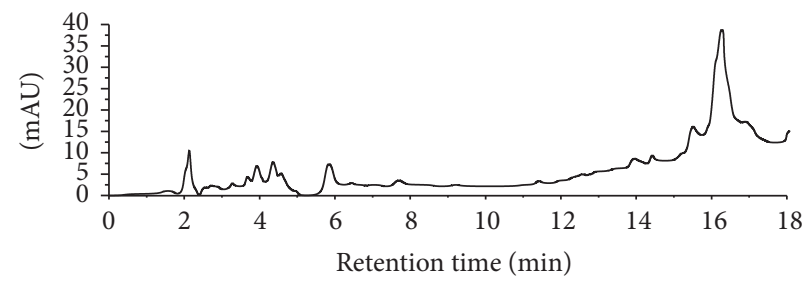

(d)

FIGURE 1: HPLC/DAD chromatogram of phenolic compounds in camellia oil cake. Detection was at $280 \mathrm{~nm}$. (a) Standards of phenolic acids. Peak: (1) gallic acid; (2) coumaric acid; (3) catechin; (4) chlorogenic acid; (5) epicatechin; (6) rutin; (7) ferulic acid; (8) naringenin; (9) kaempferol acid. (b) Isopropanol extract (IE). Peak: (3) catechin; (5) epicatechin; (8) naringenin. (c) Normal hexane extract (NE). Peak: (5) epicatechin. (d) Diethyl ether extract (DE).

TABLE 2: Phenolic compound content (mg/g dried SCE).

\begin{tabular}{lccc}
\hline Compounds & IE $(\mathrm{mg} / \mathrm{g})^{\mathrm{A}}$ & $\mathrm{NE}(\mathrm{mg} / \mathrm{g})$ & $\mathrm{DE}(\mathrm{mg} / \mathrm{g})$ \\
\hline Epicatechin & $8.64 \pm 0.03^{\mathrm{a}}$ & $9.32 \pm 0.12^{\mathrm{a}}$ & $\mathrm{ND}^{\mathrm{B}}$ \\
Naringenin & $2.71 \pm 0.05^{\mathrm{c}}$ & $\mathrm{ND}$ & $0.38 \pm 0.03^{\mathrm{b}}$ \\
Catechin & $4.00 \pm 0.04^{\mathrm{b}}$ & $0.60 \pm 0.03^{\mathrm{b}}$ & $0.73 \pm 0.04^{\mathrm{a}}$ \\
\hline
\end{tabular}

${ }^{\mathrm{A}}$ Assays were performed in triplicate. Mean \pm SD values in the same column with different superscript letter are significantly different $(p<0.05) ;{ }^{B} \mathrm{ND}$ : not detected.

3.3. Total Antioxidant Power. The ferric reducing antioxidant power (FRAP) assay is often used to determine the antioxidant power on the basis of their electron-donating ability [21]. The principle of the FRAP assay is that the electrons donated from antioxidants (defatted seed extracts) are capable of reducing ferric ions $\left(\mathrm{Fe}^{3+}\right)$ to ferrous ions $\left(\mathrm{Fe}^{2+}\right)$. Through the standard curve of the ferric reducing antioxidant power, the total antioxidant powers of BHT and the three extracts are shown in Figure 2. BHT is one of the most effective and popular antioxidants used in the food system. As reported, BHT is not the most suitable reference in FRAP evaluation when compared with that of other synthetic antioxidants. However, BHT was usually used as the positive control in FRAP evaluation and showed good FRAP values [22-25] (Halliwell and Gutteridge, 1985). Data presented in Figure 2 showed that the FRAP values of the three defatted seed extracts were significantly $(p>0.05)$ different. IE has the highest FRAP values $(3.29 \pm 0.12 \mathrm{mM} \mathrm{TEAC/g}$ dried SCE $)$ compared with NE $(2.26 \pm 0.19 \mathrm{mM} \mathrm{TEAC/g}$ dried SCE) and $\mathrm{DE}(0.89 \pm 0.15 \mathrm{mM} \mathrm{TEAC} / \mathrm{g}$ dried SCE$)$. According to the result of the HPLC-DAD measurement (Table 2), three main phenolic compounds were epicatechin, naringenin, and catechin. In addition, no significant $(p>0.05)$ difference between the FRAP values of IE and BHT $(3.63 \pm 0.21 \mathrm{mM}$

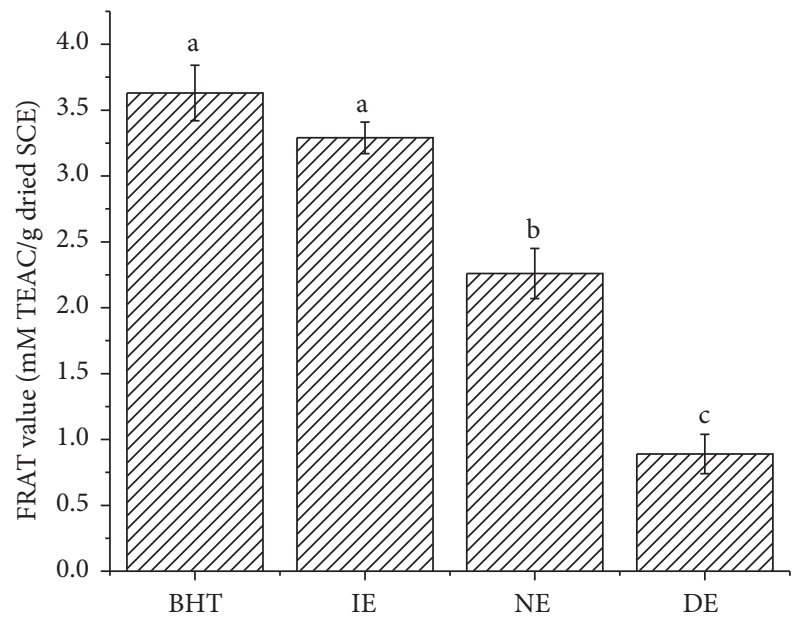

FIGURE 2: The FRAP values of camellia oil cake phenolic extracts and BHT on corn oil (BHT, butylated hydroxytoluene; IE, isopropanol extract; NE, normal hexane extract; DE, diethyl ether extract; TEAC, Trolox equivalent antioxidant capacity). The data are averages and standard deviations of triplicate measurements. Values in each bar with different superscript letters $(a, b, c)$ are significantly different $(p<0.05)$.

TEAC/g dried SCE) was observed, which suggested that IE could be potentially employed as a substitute for synthetic antioxidants in the food system.

3.4. Peroxide Value (PV). During the storage of corn oil, a series of free radical chain reactions occurred, which resulted in a great number of oxidation compounds. The antioxidant effects of phenolic compounds of SCE were assessed using the peroxide value $(\mathrm{PV})$ to determine the primary oxidation products [26]. Hydroperoxides are the primary oxidation 


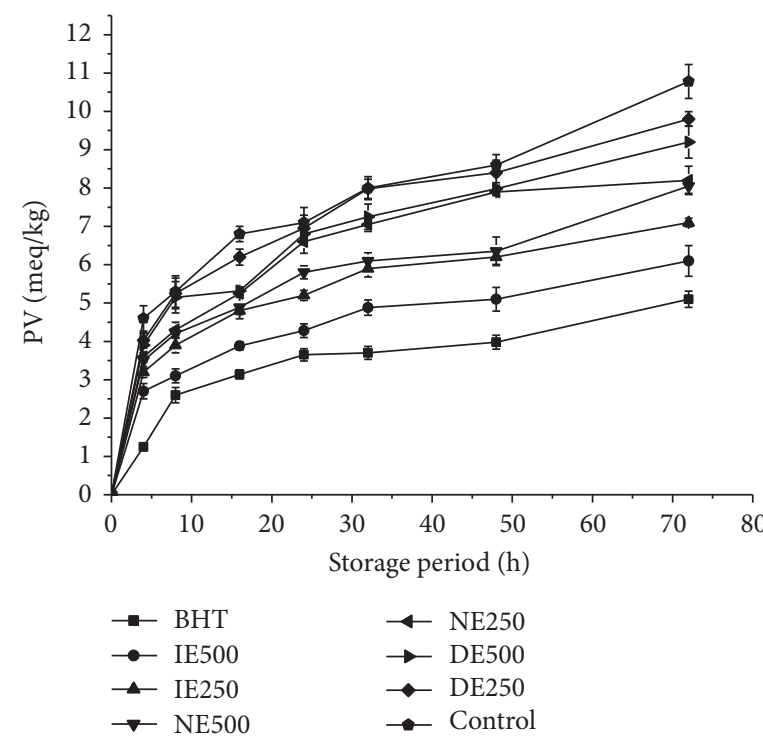

(a)

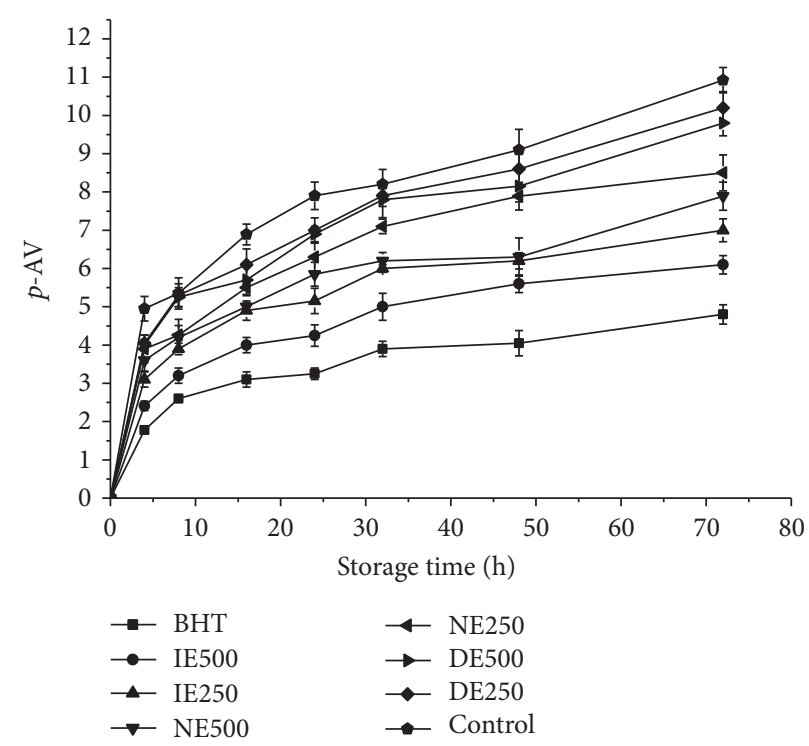

(b)

Figure 3: The changes of PV (a) and p-AV (b) during different storage time (h) (BHT, butylated hydroxytoluene; IE, isopropanol extract; NE, normal hexane extract; DE, diethyl ether extract).

products of lipid oxidation, and their content is often used as an indicator for the initial stages of oxidation. The effect of SCE and BHT on the development of PV of corn oil during storage at $50^{\circ} \mathrm{C}$ is shown in Figure 3. PV in all samples increased as the storage time was extended. This result may be attributed to the formation of hydroperoxides during primary oxidation processes. At all stages, highest PV was observed for the control sample, followed by DE-250, DE500, NE-250, NE-500, IE-250, IE-500, and BHT. The result suggested that, to some extent, PV depends on the category rather than the concentrations of antioxidants. As shown in Figure 3, PV of the control increased to $10.67 \pm 0.13 \mathrm{meq} / \mathrm{kg}$ after $72 \mathrm{~h}$ of storage. Significant differences $(p<0.05)$ were found between the control and other oil samples to which IE, NE, DE, or BHT was added, thus revealing the good antioxidant efficacy of the antioxidants in stabilization of corn oil. The synthetic antioxidant BHT showed a lower PV $(5.17 \pm 0.08 \mathrm{meq} / \mathrm{kg})$ relative to the other tested samples. IE and NE extracts were found to be more effective (with less PVs) than DE that had higher PVs.

For concentration, lower PVs were obtained when the extract concentrations were high (NE, DE, and IE). IE500 showed the best effect in lowering peroxide formation compared with the other samples. IE500 gave a PV of $6.28 \pm$ $0.12 \mathrm{meq} / \mathrm{kg}$ at $72 \mathrm{~h}$, whereas the corresponding values of the control sample were $10.67 \pm 0.13 \mathrm{meq} / \mathrm{kg}$. DE250 demonstrated the worst effect and gave a PV of $9.76 \pm 0.31 \mathrm{meq} / \mathrm{kg}$ at $72 \mathrm{~h}$. From the analysis above, we may conclude that extracts from defatted seed at $0.25 \%$ and $0.5 \%(\mathrm{w} / \mathrm{v})$ concentrations were effective in stabilization of corn oil during storage at $50^{\circ} \mathrm{C}$ and that defatted seed extracts at higher concentrations were better at inhibiting corn oil oxidation in the initial stage. IE displayed the best antioxidant activity among the three solvent extracts, which is consistent with the results of FRAP.
3.5. Conjugated Dienes $(C D)$ Values. CD value is also a good indicator of oxidative deterioration of oils in the initial stages, and it may thus also be a good indicator of the effectiveness of antioxidants [27]. Table 3 indicates that CD of corn oil with defatted seed extracts and BHT varies after storage for 0,24 , 48 , and $72 \mathrm{~h}$ at $50^{\circ} \mathrm{C}$. The $\mathrm{CD}$ values of all samples increased with storage time, which may reflect the lipid oxidation process. The control sample exhibited the highest $C D$ value in all storage stages and showed a sixfold increase after $72 \mathrm{~h}(12.10 \pm$ $0.64 \%)$, relative to the initial period $(2.15 \pm 0.49 \%)$. High values of $\mathrm{CD}$ may be related to the presence of higher contents of polyunsaturated fatty acids in the oil samples [8] (Liu and White, 1992). Compared to the control, the CD values of the corn oil samples containing defatted seed extracts or BHT showed lower increase during the same storage period. After storage for $72 \mathrm{~h}$, the lowest CD was observed for BHT sample $(5.58 \pm 0.30 \%)$ followed by IE $(7.05 \pm 0.33 \%)$, NE $(8.71 \pm 0.39 \%)$, and DE $(10.83 \pm 0.40 \%)$. The $\mathrm{CD}$ results were consistent with the measures of PV.

3.6. Secondary Oxidation Products Determination. In this study, secondary oxidation products were assessed using thiobarbituric acid reactive substances (TBARS) and $p$ anisidine value $(p-\mathrm{AV})$. TBARS is the most widely used method for measuring secondary oxidation products, which may contribute to the off-flavor of oxidized oil. As shown in Table 3, TBARS for all samples increased gradually as the storage period was extended $(0 \sim 72 \mathrm{~h})$. As observed for the primary oxidation product ( $\mathrm{PV}$ and $\mathrm{CD}$ values), the control showed the highest level of TBARS at all storage times, and the values for the samples treated with extracts and antioxidant were significantly lower than those of the control. The TBARS of IE stabilized corn oil increased from $0.30 \pm 0.12$ to $1.08 \pm 0.46 \mu \mathrm{mol} / \mathrm{g}$ oil. This was lower than that of NE and 
TABLE 3: Conjugated diene (CD) and TBARS values of corn oil stabilized by camellia oil cake phenolic extracts $(0.5 \%)$ and BHT (0.02\%) during different storage time at $50^{\circ} \mathrm{C}^{\mathrm{A}}$.

\begin{tabular}{lccccc}
\hline Time $(\mathrm{h})$ & BHT $^{\mathrm{B}}$ & Control & NE & IE & \\
\hline & & CD values $\%$ of conjugated dienoic acid) & & \\
0 & $2.15 \pm 0.49^{\mathrm{a}}$ & $2.15 \pm 0.49^{\mathrm{a}}$ & $2.30 \pm 0.22^{\mathrm{a}}$ & $2.03 \pm 0.23^{\mathrm{a}}$ & $2.25 \pm 0.18^{\mathrm{a}}$ \\
24 & $3.20 \pm 0.22^{\mathrm{e}}$ & $4.67 \pm 0.20^{\mathrm{a}}$ & $3.83 \pm 0.21^{\mathrm{c}}$ & $3.60 \pm 0.18^{\mathrm{d}}$ & $4.28 \pm 0.25^{\mathrm{b}}$ \\
48 & $5.08 \pm 0.38^{\mathrm{e}}$ & $8.05 \pm 0.78^{\mathrm{a}}$ & $6.88 \pm 0.48^{\mathrm{c}}$ & $6.48 \pm 0.15^{\mathrm{d}}$ & $7.33 \pm 0.28^{\mathrm{b}}$ \\
72 & $5.58 \pm 0.30^{\mathrm{e}}$ & $12.10 \pm 0.64^{\mathrm{a}}$ & $8.71 \pm 0.39^{\mathrm{c}}$ & $7.05 \pm 0.33^{\mathrm{d}}$ & $10.83 \pm 0.40^{\mathrm{b}}$ \\
\hline & & TBARS value $(\mu \mathrm{mol} / \mathrm{g}$ oil) & & \\
0 & $0.29 \pm 0.10^{\mathrm{a}}$ & $0.34 \pm 0.16^{\mathrm{a}}$ & $0.27 \pm 0.13^{\mathrm{a}}$ & $0.30 \pm 0.12^{\mathrm{a}}$ & $0.30 \pm 0.14^{\mathrm{a}}$ \\
24 & $0.39 \pm 0.17^{\mathrm{e}}$ & $0.85 \pm 0.24^{\mathrm{a}}$ & $0.67 \pm 0.23^{\mathrm{c}}$ & $0.58 \pm 0.24^{\mathrm{d}}$ & $0.79 \pm 0.26^{\mathrm{b}}$ \\
48 & $0.55 \pm 0.29^{\mathrm{e}}$ & $1.19 \pm 0.38^{\mathrm{a}}$ & $0.73 \pm 0.41^{\mathrm{c}}$ & $0.62 \pm 0.24^{\mathrm{d}}$ & $1.08 \pm 0.43^{\mathrm{b}}$ \\
72 & $0.77 \pm 0.22^{\mathrm{e}}$ & $1.92 \pm 0.47^{\mathrm{a}}$ & $1.48 \pm 0.47^{\mathrm{c}}$ & $1.08 \pm 0.46^{\mathrm{d}}$ & $1.67 \pm 0.28^{\mathrm{b}}$ \\
\hline
\end{tabular}

${ }^{\mathrm{A}}$ Assays were performed in triplicate. Mean \pm SD values in the same column with different superscript letter are significantly different $(p<0.05)$; ${ }^{\mathrm{B}} \mathrm{BHT}$, butylated hydroxytoluene; IE, isopropanol extract; NE, normal hexane extract; DE, diethyl ether extract.

DE samples $(1.48 \pm 0.47$ and $1.67 \pm 0.28 \mu \mathrm{mol} / \mathrm{g}$ oil, resp. $)$ but higher than that of BHT sample $(0.77 \pm 0.22 \mu \mathrm{mol} / \mathrm{g}$ oil $)$ after $72 \mathrm{~h}$. These results suggested that the antioxidant activity of the defatted seed extracts and synthetic antioxidant was in the following order: BHT $>$ IE $>$ NE $>$ DE.

The $p$-AV is also useful for assessing oil at the secondary stage of oxidation. The $p$-AV of corn oil samples stabilized by defatted seed extracts and BHT during different storage times is shown in Figure 3(b). As shown in Figure 3(b), across all storage times, the highest $p$-AV was observed for controls, followed by DE, NE, and IE, indicating that IE and NE were more effective than DE. Relative to BHT, the phenolic extracts obtained from defatted seed extracts seemed to be less effective in inhibiting secondary products. In addition, $p$-AV decreased as the concentration of extracts increased. These results suggested that defatted seed extracts with certain concentration ranges could effectively improve the stabilization of corn oil.

\section{Conclusion}

Three solvents (isopropanol, hexane, and diethyl ether) were used to extract active compounds from defatted seeds of Camellia oleifera Abel. The results showed that isopropanolic extract (IE) exhibited the highest yield of total phenolic compounds $(9.23 \pm 0.33 \mathrm{mg} / \mathrm{g})$, followed by normal hexane extract $(6.45 \pm 0.61 \mathrm{mg} / \mathrm{g})$ and diethyl ether extract $(3.86 \pm 0.48 \mathrm{mg} / \mathrm{g})$. Three predominant phenolic compounds (epicatechin, naringenin, and catechin) from the defatted seed extracts were identified using the HPLC-DAD method. In addition, the antioxidant efficacy of IE, NE, and DE has been estimated in stabilization of corn oil by monitoring the primary and secondary oxidation products of oil. The peroxide value (PV), anisidine value $(\mathrm{AV})$, conjugated dienes (CD), and thiobarbituric acid reactive substances (TBARS) each indicated a similar trend in the antioxidant activity of the three extracts: IE $>\mathrm{NE}>\mathrm{DE}$. The results revealed that IE of defatted seed of Camellia oleifera Abel is a useful antioxidant for the stabilization of corn oil.

\section{Additional Points}

Practical Applications. The seeds of Camellia oleifera constitute an important oil material that is extensively used to produce a specific type of cooking oil (tea oil), whose beneficial unsaturated fatty acids are comparable to those of olive oil. Tea oil is a good raw material for industrial use and is used to manufacture soap, margarine, hair oil, lubricants, and paint and in the syntheses of other high-molecular weight compounds.

\section{Disclosure}

The authors alone are responsible for the content and writing of the paper.

\section{Conflicts of Interest}

The authors report no conflicts of interest.

\section{Acknowledgments}

This research was supported by the National Natural Science Foundation of China (ID: 31760480; 31640061), the Natural Science Foundation of Hainan Province of China (ID: 317002), the Hainan Key Scientific and Technological Projects of China (ID: ZDYF2016096), and the Hainan University Start-Up Scientific Research Projects of China (ID: kyqd1551; kyqd1630).

\section{References}

[1] F. S. Matalgyto and A. S. Al-Khalifa, "Effect of microwave oven heating on stability of some oils and fats," Arab Gulf Journal of Scientific Research, vol. 16, no. 2, pp. 431-450, 1998.

[2] F. Shahidi, C. Desilva, and R. Amarowicz, "Antioxidant activity of extracts of defatted seeds of Niger (Guizotia abyssinica)," Journal of the American Oil Chemists' Society, vol. 80, no. 5, pp. 443-450, 2003. 
[3] I. G. Roussis, P. C. Tzimas, and K. Soulti, "Antioxidant activity of white wine extracts and some phenolic acids toward corn oil oxidation," Journal of Food Processing and Preservation, vol. 32, no. 4, pp. 535-545, 2008.

[4] Y. He and F. Shahidi, "Antioxidant activity of green tea and its catechins in a fish meat model system," Journal of Agricultural and Food Chemistry, vol. 45, no. 11, pp. 4262-4266, 1997.

[5] B. Halliwell and J. M. C. Gutteridge, "Antioxidant defenses," in Free Radicals in Biology and Medicine, pp. 105-245, Oxford University Press, New York, NY, USA, 3rd edition, 1999.

[6] F. Shahidi, U. N. Wanasundara, and R. Amarowicz, "Natural antioxidants from low-pungency mustard flour," Food Research International, vol. 27, no. 5, pp. 489-493, 1994.

[7] U. Wanasundara, R. Amarowicz, and F. Shahidi, "Isolation and identification of an antioxidative component in canola meal," Journal of Agricultural and Food Chemistry, vol. 42, no. 6, pp. 1285-1290, 1994.

[8] S. Iqbal and M. I. Bhanger, "Stabilization of sunflower oil by garlic extract during accelerated storage," Food Chemistry, vol. 100, no. 1, pp. 246-254, 2007.

[9] P. Zandi and M. H. Gordon, "Antioxidant activity of extracts from old tea leaves," Food Chemistry, vol. 64, no. 3, pp. 285-288, 1999.

[10] S. Iqbal, M. I. Bhanger, and F. Anwar, "Antioxidant properties and components of some commercially available varieties of rice bran in Pakistan," Food Chemistry, vol. 93, no. 2, pp. 265272, 2005.

[11] S. Iqbal, M. I. Bhanger, and F. Anwar, "Antioxidant properties and components of bran extracts from selected wheat varieties commercially available in Pakistan," LWT-Food Science and Technology, vol. 40, no. 2, pp. 361-367, 2007.

[12] P.-D. Duh and G.-C. Yen, "Antioxidant efficacy of methanolic extracts of peanut hulls in soybean and peanut oils," JAOCS, Journal of the American Oil Chemists' Society, vol. 74, no. 6, pp. 745-748, 1997.

[13] X. Jin, "Bioactivities of water-soluble polysaccharides from fruit shell of Camellia oleifera Abel: Antitumor and antioxidant activities," Carbohydrate Polymers, vol. 87, no. 3, pp. 2198-2201, 2012.

[14] D.-F. Gao, M. Xu, P. Zhao et al., "Kaempferol acetylated glycosides from the seed cake of Camellia oleifera," Food Chemistry, vol. 124, no. 2, pp. 432-436, 2011.

[15] V. L. Singleton and J. R. Rossi, "Colorimetry of total phenolics with phosphomolibdic-phosphothungstic acid," American Journal of Enology and Viticulture, vol. 16, pp. 144-158, 1965.

[16] R. Chirinos, I. Betalleluz-Pallardel, A. Huamán, C. Arbizu, R. Pedreschi, and D. Campos, "HPLC-DAD characterisation of phenolic compounds from Andean oca (Oxalis tuberosa Mol.) tubers and their contribution to the antioxidant capacity," Food Chemistry, vol. 113, no. 4, pp. 1243-1251, 2009.

[17] S. M. Mohsen and A. S. M. Ammar, "Total phenolic contents and antioxidant activity of corn tassel extracts," Food Chemistry, vol. 112, no. 3, pp. 595-598, 2009.

[18] S. Someya, Y. Yoshiki, and K. Okubo, "Antioxidant compounds from bananas (Musa Cavendish)," Food Chemistry, vol. 79, no. 3, pp. 351-354, 2002.

[19] S. Iqbal, M. I. Bhanger, M. Akhtar, F. Anwar, K. R. Ahmed, and T. Anwer, "Antioxidant properties of methanolic extracts from leaves of Rhazya stricta," Journal of Medicinal Food, vol. 9, no. 2, pp. 270-275, 2006.
[20] G. M. Weisz, D. R. Kammerer, and R. Carle, "Identification and quantification of phenolic compounds from sunflower (Helianthus annuus L.) kernels and shells by HPLC-DAD/ESIMSn," Food Chemistry, vol. 115, no. 2, pp. 758-765, 2009.

[21] L. Müller, K. Fröhlich, and V. Böhm, "Comparative antioxidant activities of carotenoids measured by ferric reducing antioxidant power (FRAP), ABTS bleaching assay ( $\alpha$ TEAC), DPPH assay and peroxyl radical scavenging assay," Food Chemistry, vol. 129, no. 1, pp. 139-148, 2011.

[22] L. Liang, Z. Zhang, and H. Wang, "Antioxidant activities of extracts and subfractions from Inonotus Obliquus," International Journal of Food Sciences and Nutrition, vol. 60, no. 2, pp. 175-184, 2009.

[23] R. Borneo, A. E. León, A. Aguirre, P. Ribotta, and J. J. Cantero, "Antioxidant capacity of medicinal plants from the Province of Córdoba (Argentina) and their in vitro testing in a model food system," Food Chemistry, vol. 112, no. 3, pp. 664-670, 2009.

[24] Y. Wang, S. Huang, S. Shao, L. Qian, and P. Xu, "Studies on bioactivities of tea (Camellia sinensis L.) fruit peel extracts: Antioxidant activity and inhibitory potential against $\alpha$-glucosidase and $\alpha$-amylase in vitro," Industrial Crops and Products, vol. 37, no. 1, pp. 520-526, 2012.

[25] Z. Yang and W. Zhai, "Identification and antioxidant activity of anthocyanins extracted from the seed and cob of purple corn (Zea mays L.)," Innovative Food Science and Emerging Technologies, vol. 11, no. 1, pp. 169-176, 2010.

[26] M. H. Gordon, F. Paiva-Martins, and M. Almeida, "Antioxidant activity of hydroxytyrosol acetate compared with that of other olive oil polyphenols," Journal of Agricultural and Food Chemistry, vol. 49, no. 5, pp. 2480-2485, 2001.

[27] S. Iqbal, S. Haleem, M. Akhtar, M. Zia-ul-Haq, and J. Akbar, "Efficiency of pomegranate peel extracts in stabilization of sunflower oil under accelerated conditions," Food Research International, vol. 41, no. 2, pp. 194-200, 2008. 

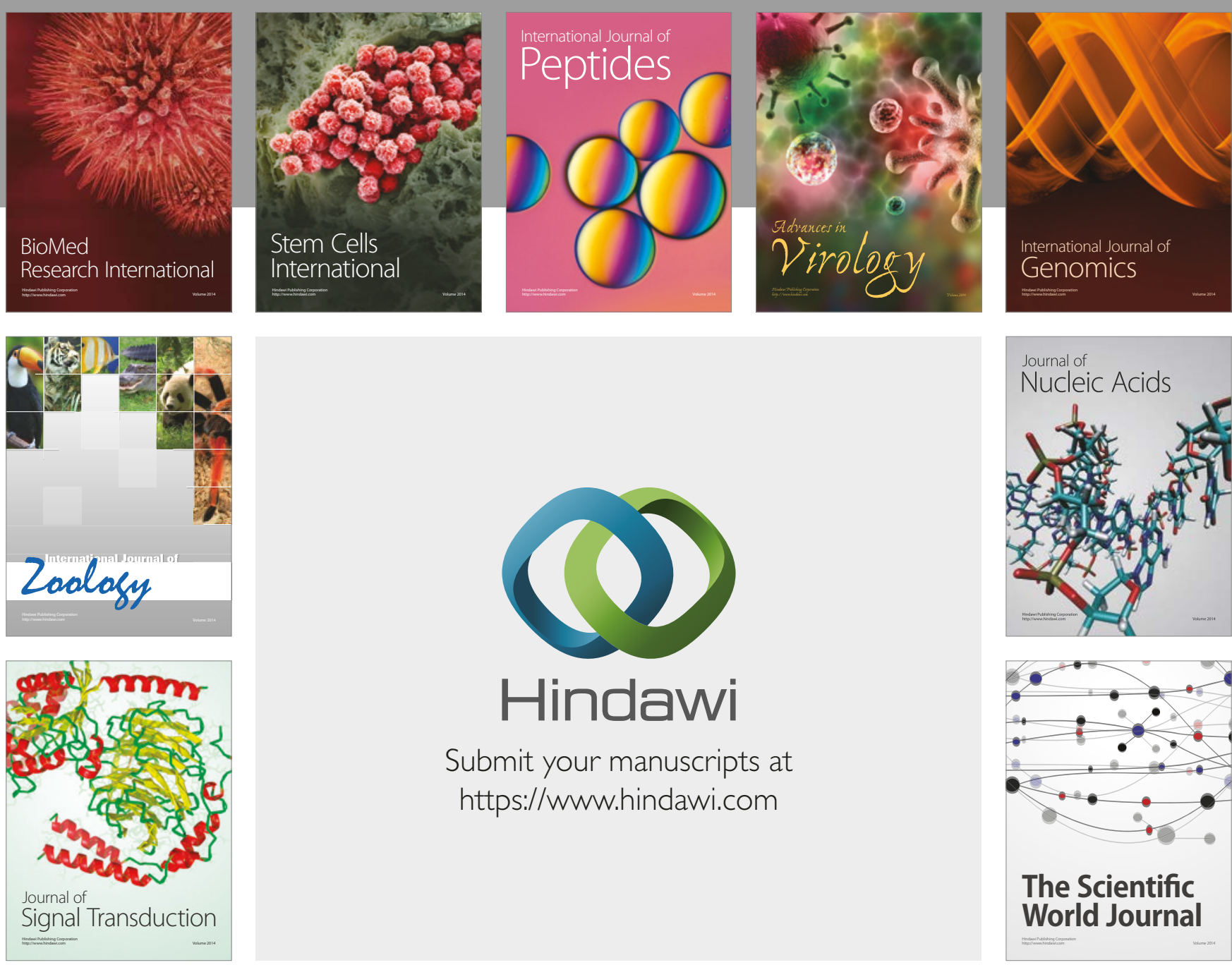

Submit your manuscripts at

https://www.hindawi.com
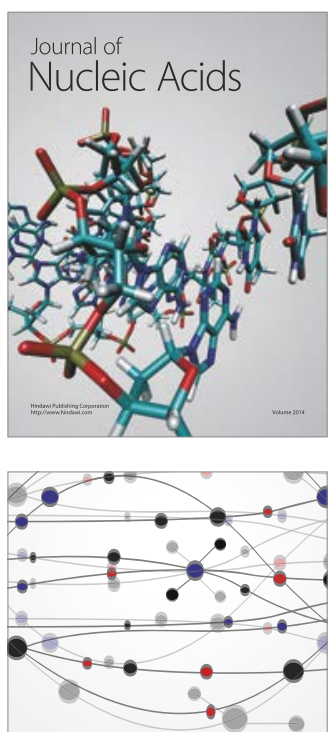

The Scientific World Journal

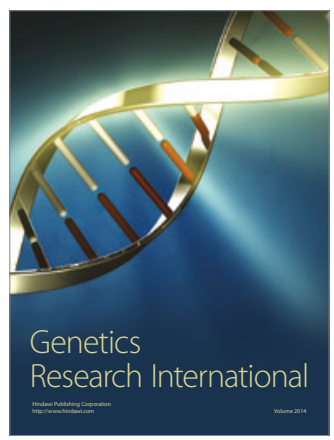

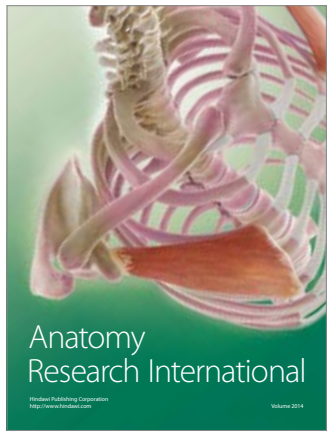

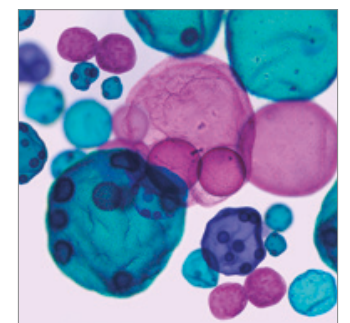

International Journal of Microbiology
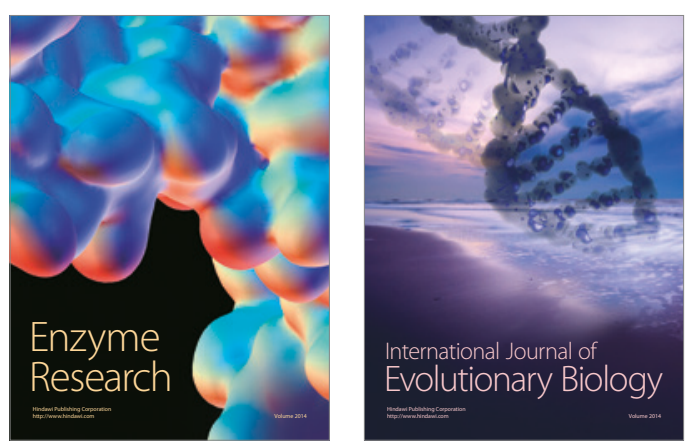
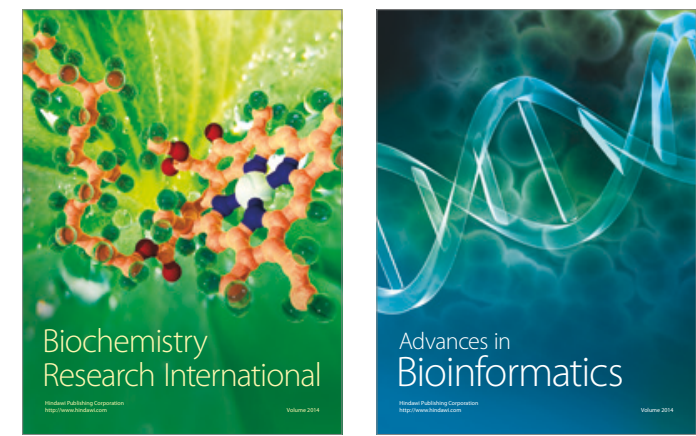

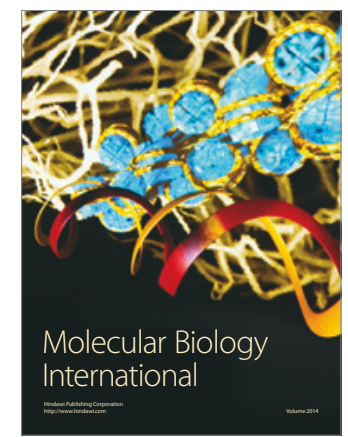

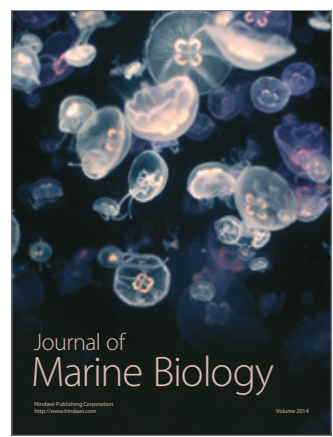

